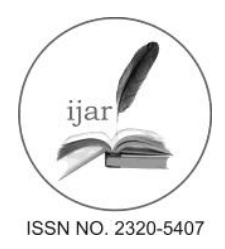

\section{Journal homepage: http://www.journalijar.com Journal DOI: 10.21474/IJAR01}

RESEARCH ARTICLE

\title{
Experimental investigation of multi cylinder S.I. Engine emissions by using oxygen enriched air
}

\author{
Abhijeet Padolkar', Abhishek Waghmare', Peeyoosh Tekale ${ }^{1}$, Ravikiran Panchal ${ }^{1}$, P.P.Patunkar ${ }^{2}$. \\ 1. Students, Currently Pursuing Bachelors Degree Program in Mechanical Engineering, Sinhgad Institute of \\ Technology and Science, Narhe, Pune, India. \\ 2. Assistant professor, Department of Mechanical Engineering, Sinhgad Institute of Technology and Science, \\ Narhe, Pune, India.
}

\section{Manuscript Info}

Manuscript History:

Received: 18 March 2016

Final Accepted: 26 April 2016

Published Online: May 2016

Key words:

S.I Engine, Emissions, Pollutants, Oxy-enriched air, Blending, Oxygen enrichment.

*Corresponding Author

Abhijeet Padolkar.

\begin{abstract}
This research paper gives an explanation of the formation process of toxic exhaust gas components during combustion process of oxygen-enriched mixtures in SI engine. Emissions from the exhaust of internal combustion engine affects the environment globally and also it has negative impact on human health.. Various strategies have been being developed to regulate the pollution in the urban development. Increase the concentration of oxygen in the intake air is also one of the methods to reduce emissions of $\mathrm{CO}$ and $\mathrm{HC}$. In order to reduce the emissions the oxygen was supplied at different flow rates i.e.at $31 \mathrm{pm}, 61 \mathrm{pm}$ and $91 \mathrm{pm}$.Investigation work shows that carbon monoxide(CO) emissions decreases at increased amount of oxygen concentration in the intake air but at the same time carbon dioxide $\left(\mathrm{CO}_{2}\right)$ emissions increases due to proper combustion in the combustion chamber.
\end{abstract}

Copy Right, IJAR, 2016,. All rights reserved.

\section{Introduction:-}

The rapid urbanization in India has resulted in a tremendous increase the number of motor vehicles. Poor air quality in the urban development is the result of increase in emissions of the pollutants from internal combustion engine. The country has however taken a number of measures for the improvement of the air quality in cities. These include, right from the improvement in the fuel quality, formulation of necessary legislation and enforcement of vehicle emission standards; improved traffic planning and management etc. Oxygenized air also helps in reduction of emissions of pollutants from exhaust of engine.

Main pollutants contributed by the internal combustion engine are as follows:

1. Oxides of Nitrogen (NOx)

2. Carbon monoxide (CO)

3. Hydrocarbons ( $\mathrm{HC})$

4. Carbon dioxide $\left(\mathrm{CO}_{2}\right)$

Oxides of Nitrogen (NOx):-

Oxides of Nitrogen: High temperature in the combustion chamber is one of reason for increase in emissions of oxides of nitrogen. Nitrogen molecule and oxygen molecule combine together to form oxides of nitrogen at temperature higher than 1600 degree Celsius in the combustion chamber Reactions taking place in the combustion chamber forming NOx are:

$$
\begin{gathered}
\mathrm{N}_{2}+\mathrm{O} \rightarrow \mathrm{NO}+\mathrm{N} \\
\mathrm{N}+\mathrm{O} 2 \rightarrow \mathrm{NO}+\mathrm{O} \\
\mathrm{N}+\mathrm{OH} \rightarrow \mathrm{NO}+\mathrm{H}[5]
\end{gathered}
$$




\section{Carbon monoxide (CO):-}

Lack of oxygen inside the cylinder results into incomplete combustion and incomplete combustion results into increase in the emissions of carbon monoxide (CO). The reaction can be represented as,

$$
\mathrm{C} 2+1 / 2 \mathrm{O} 2 \rightarrow \mathrm{CO}[5]
$$

\section{Hydrocarbons (HC):}

Hydro carbon is actually the fuel that we use to run the engine. Incomplete combustion also results in the formation of hydrocarbons (HC) which results in increase in pollution of atmosphere. [5]

\section{Carbon Dioxide $\left(\mathrm{CO}_{2}\right)$ :}

Carbon dioxide forms due to complete combustion of fuel. Emissions of the greenhouse gas $\mathrm{CO} 2$ have increased by $36.5 \%$ in the period between 1990 to 2004 [3].Carbon dioxide not only affects human health but also responsible for increase in temperature of earth.

\section{Local and global effects of the exhaust emissions of the $i$. c. engine :-}

Increase in emissions of the toxic compounds like oxides of Nitrogen (NOx), Carbon monoxide (CO), Carbon Dioxide (CO2) from the exhaust of the internal combustion engine affects the environment locally and globally.

\section{Local effects:-}

Increase in emissions of the toxic pollutants results into increase in cardiac as well as respiratory problems in the human being. The use of the vehicles is also increasing day by day.

Increase in emissions of the carbon monoxide affects the cardio vascular system, exacerbating cardiovascular disease symptoms, particularly angina; may also particularly affect fetuses, sick, anemic and young children, affects nervous system impairing physical coordination, vision and judgments, creating nausea and headaches, reducing productivity and increasing personal discomfort[3]

Increased susceptibility to infections, pulmonary diseases, impairment of lung function and eye, nose and throat irritations these are effects of oxides of nitrogen on the human health.[3]

Decreased lung function, Heart attacks, development of chronic bronchitis, increase in respiratory problems like irritation in passages, coughing and breathing are the main health problems which are caused due to increase in emissions of the particulate matter(PM). High level emissions of these particulate materials may result into death.[4]

\section{Global effects:-}

The emissions from vehicles also affect the environment globally. Increase in number of vehicles results into increase in concentration of $\mathrm{CO}_{2}$ by $2 \mathrm{ppm}$ (parts per million) annually. Transport contributed to an estimated $19 \%$ of global GHG (greenhouse gas) emissions in 1971, but rose to 25\% in 2006[4].Therefore it is very necessary to develop new techniques to reduce $\mathrm{CO}_{2}$ emissions from the vehicles.

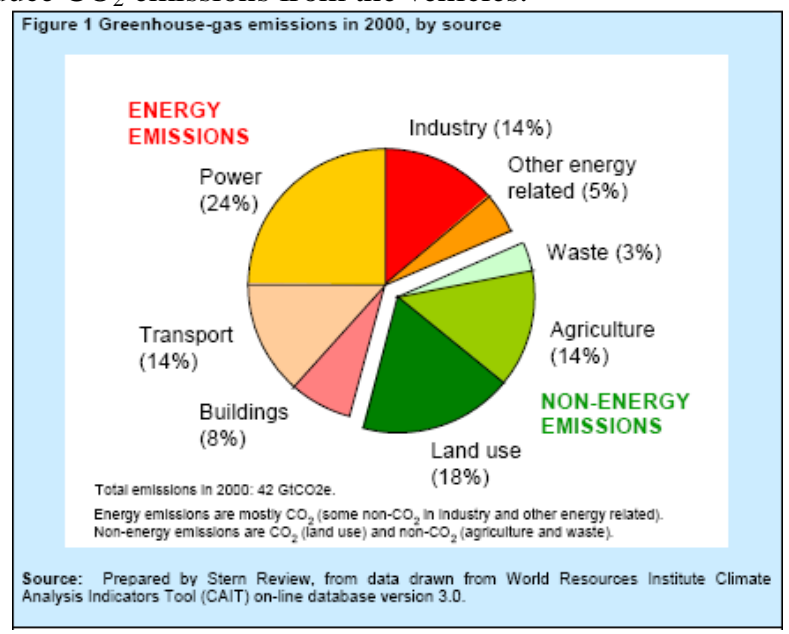

Fig 1: Global emissions of GHG's from different sectors [3] 
$14 \%$ of the green house emissions come only from transport sector. Emissions of the greenhouse gas CO2 have increased by $36.5 \%$ in the period between 1990 to 2004.The world average temperature has risen by about $1 \mathrm{~F}^{\circ}$ over the past century. Burning of fossil fuels results into increase in the emissions of the greenhouse gases like carbon dioxide, oxides of nitrogen, chlorofluorocarbons.[4]

\section{Transport $\mathrm{CO}_{2}$-Emissions by mode (2005)}

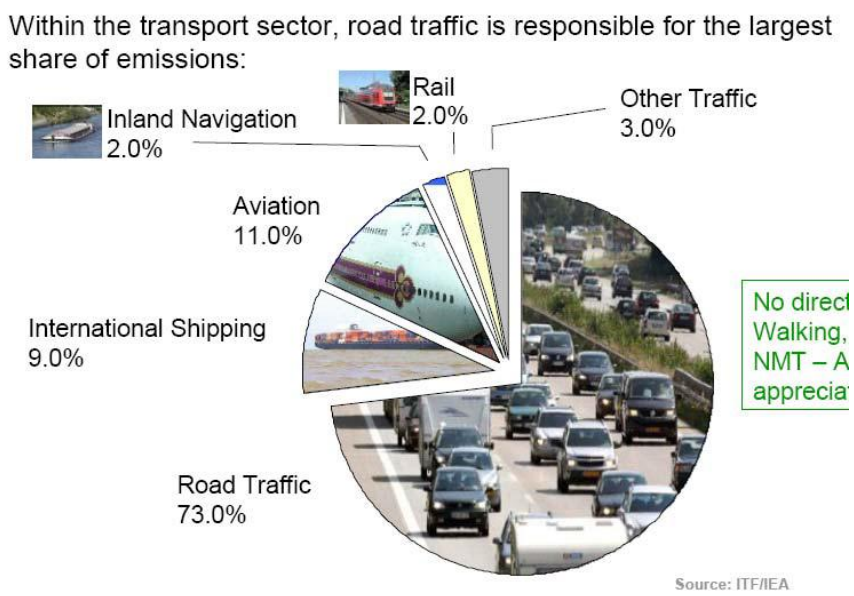

Figure2: Global GHG's emissions from Transport sector(Mode-Wise)[3] $73 \%$ of the CO2emmisions come only from the road traffic

\section{Literature review:-}

Anil KB [5]: In an internal combustion engine, air from atmosphere and fuel from fuel tank equipped with it mixes to form air-fuel mixture. In normal conditions the amount of oxygen in the air is $21 \%$ by volume. Oxides of nitrogen (NOx), Carbon monoxide $(\mathrm{CO})$, Carbon dioxide $\left(\mathrm{CO}_{2}\right)$, Hydrocarbons $(\mathrm{HC})$ are the main toxic pollutants which are responsible for today's polluted atmosphere. The experimental work was done on 4 cylinder spark ignition air cooled engine. It was observed that the incomplete combustion occurred both at very low and very high temperature. The amount of oxygen by volume was increased from $21 \%$ to $28 \%$. The ignition delay period decreased by $6 \%$ when the concentration of oxygen was increased to $28 \%$. Combustion period also decreased by $8 \%$ to $23 \%$ for the enrichment range of $24 \%$ to $28 \%$ of oxygen. Filter concept was introduced to separate the oxygen by using the cyclone separator. Separation of oxygen from oxides of nitrogen is a difficult task as the difference between the density of oxygen and nitrogen is very small. Two models were made to filter oxygen. Model 1 consists of a simple hollow type cylinder in which atmospheric air is forced to flow in circular direction. The passage of the inlet air is so designed that while the air enters in to the cylinder air executes a circular motion. Due to density difference, oxygen get separated from oxides of nitrogen.

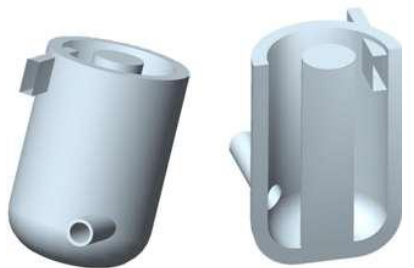

Fig 3: Model 1[5]

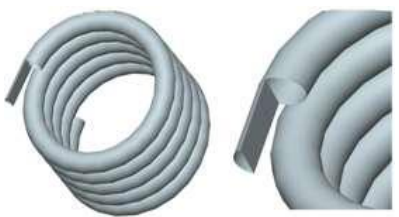

Fig 4: Model 2 [5] 
To overcome the disadvantages of model 1, model 2 was introduced. In model 2 the circular chamber was replaced by the hollow tube coiled like spring and air separating arrangement at one end of the coil.

Juhi Sharaf [6]: CO, NOx, unburned hydrocarbons and other particulate emissions from vehicles are the main pollutants which are responsible for the degradation of air quality in the urban development. These pollutants also have an negative impact on human health and global warming. Therefore it is very important to develop some new techniques for reduction in emissions from internal combustion engine. U.S. Environmental protection agency (EPA) is the first agency that describes the harmful effects of green house gases. Emissions of the harmful pollutants (mainly CO, Redesigning the engine system, cooling system and ignition system is one of the method that was explained to reduce the formation of pollutants from spark ignition engine. The methods like Crankcase emission control, Evaporative emission control, Exhaust gas recirculation were explained to reduce the CO2,NOx) from spark ignition engine. Crankcase case control, Evaporative emission control, Exhaust gas recirculation these are the methods for controlling emissions from internal combustion.

Wladyslaw Mitianiec,Krzysztof Sliwinski[7]:The main objective of this paper is to determine emissions of toxic exhaust gases like $\mathrm{CO}$ and $\mathrm{CO}_{2}$ from multi cylinder spark ignition engine before and after oxygen enrichment. The concentration of oxygen was increased from $21 \%$ to $32 \%$.By applying EGR i.e. exhaust gas recirculation system, the temperature of the cylinder decreased by great extent. Experiments were done on air cooled 2-cylinder 4-stroke spark ignition engine with different amount of oxygen and EGR ratios in order to reduce the emissions of NOx and temperature of the cylinder during combustion process. By using data which was obtained by performing various tests on the dynamometer, the simulation process was carried out. Results were compared by plotting graph the of volumetric ratios of $\mathrm{CO}, \mathrm{CO} 2, \mathrm{HC}$ and $\mathrm{NOx}$ at different $\mathrm{EGR}$ ratios but speed of the engine was kept constant i.e. 3000rpm.It was observed that the volumetric ratios of $\mathrm{CO}, \mathrm{CO} 2$ and $\mathrm{HC}$ increased with increasing the EGR ratio but the NOx content decreased with increasing EGR ratio. Emissions of toxic gases like $\mathrm{CO}$ and $\mathrm{HC}$ decreased by increasing the volume of oxygen from $21 \%$ to $32 \%$. On the other hand $\mathrm{CO} 2$ emissions increased with increase in oxygen content in the combustion chamber. Simulation test indicated the non-linear variation of mole fractions of carbon dioxide and carbon monoxide at various amount of oxygen by volume. It was also observed that mean effective pressure and break specific fuel consumption decreased with increase in volume of oxygen from $21 \%$ to $32 \%$ at constant speed of $3000 \mathrm{rpm}$.

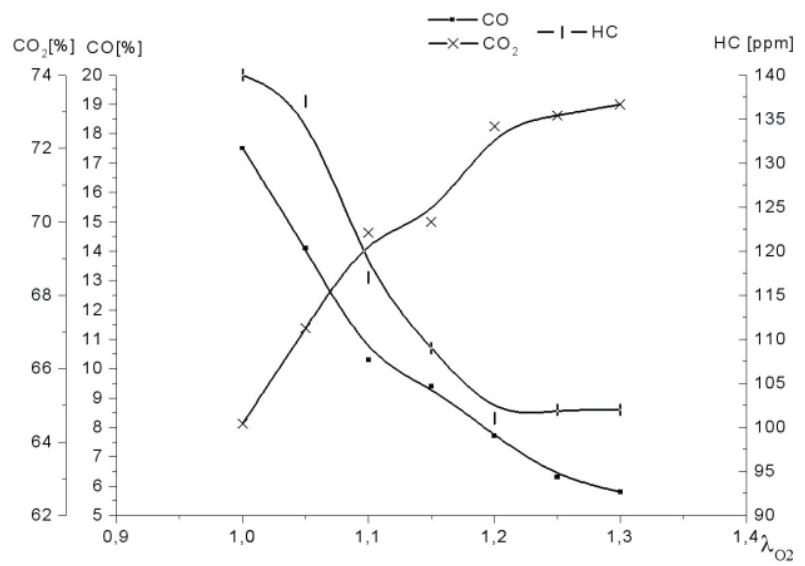

Fig 5:Volumetric fractions of $\mathrm{CO} 2, \mathrm{CO}$ and $\mathrm{HC}$ for increased $\mathrm{O} 2$ volume and at $\mathrm{n}=3000 \mathrm{rpm}[7]$

D.R.Gaikwad, H.M.Dange [8]: The experimental work was carried out on multi cylinder 4 stroke S.I. engine (MPFI i.e. multi point fuel injection).Performance of the SI engine was investigated at different mass flow rate of oxygen and the speed of the S.I. engine was also varied from $1000 \mathrm{rpm}$ to $3000 \mathrm{rpm}$. Exhaust gas emission levels were also analysed at different mass flow rates of oxygen. $\mathrm{CO}$ and $\mathrm{HC}$ are the main pollutants of the engine. After supplying the oxygen to the intake manifold it was observed that the emission levels of the main pollutants reduced by great extent. By observing all the results it was concluded that the overall performance of the spark ignition engine was enhanced when the mass flow rate of oxygen was $101 \mathrm{pm}$. 


\section{Methodology:-}

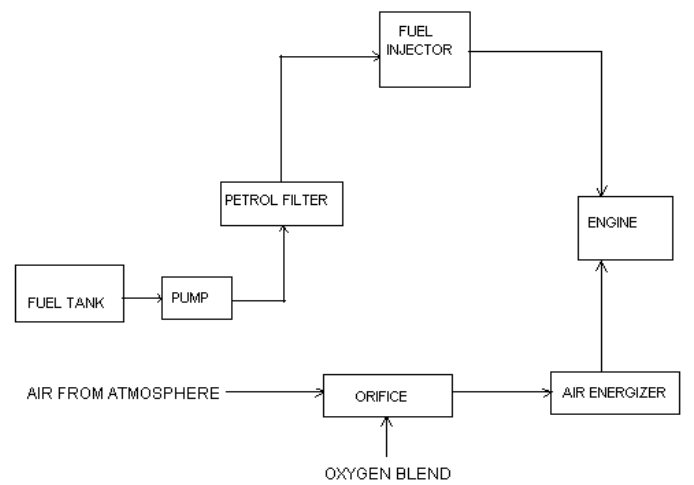

Fig 6: Block diagram

Oxygen Cylinder:- The oxygen cylinder of 7 cubic meter capacity is used for the present work. Oxygen stored at the pressure of 150psi.

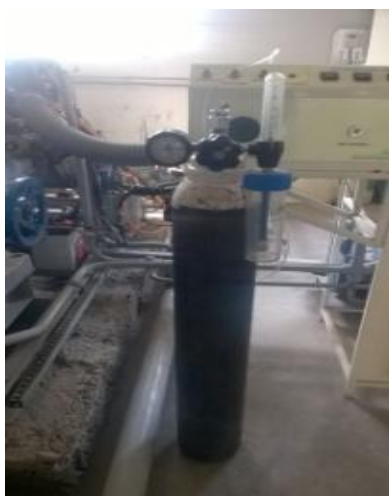

Fig 7: Oxygen cylinder with flow meter.

Distributor pipe:- The distributor pipe is placed in between oxygen cylinder flow meters and IC engine test rig air box.

Flow Meter:- Flow meter is device used to measure volume flow of gas. The principle of lifting of mass by density of gas is used in a working of flow meter. In the flow meter pressurized gas from reservoir is injected in a vertical capillary tube having ball of unit mass enclosed in it. The capillary tube is having increasing scale from bottom to top that is $0-10$ liter/min.

Mixing chamber:- The main purpose of mixing chamber is to mix oxygen in to sucked air.

Engine:- The three cylinder four stroke petrol engine test rig is used for experimental work. The oxygen from mixing chamber is then sending to suction of engine.

Exhaust gas analyser:- To analyse the $\mathrm{CO}$ and $\mathrm{CO}_{2}$ emissions from the spark ignition engine at different flow rates of oxygen, exhaust gas analyser is used. 


\section{Experimental work:-}

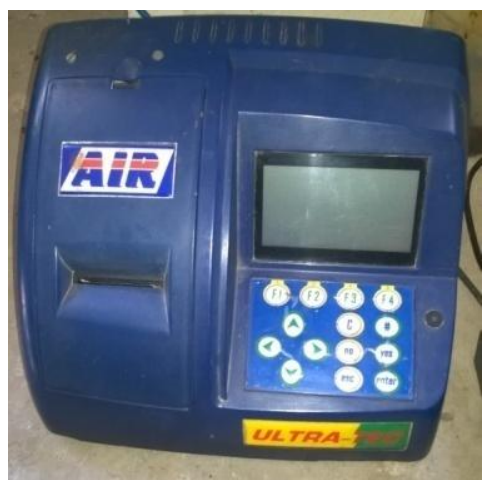

Fig 8: Exhaust gas analyser.

For performance analysis, various experiments are carried out on multi cylinder spark ignition engine at different concentrations of oxygen in the intake air.

Table1: Engine specifications

\begin{tabular}{|l|lrr|}
\hline Engine type & $\begin{array}{l}\text { Make Maruti, 3 cylinder,4 } \\
\text { stroke, Petrol MPFI }\end{array}$ \\
\hline Specifications & $\begin{array}{l}\text { Power 27KW, Torque } \\
\text { NM,796cc,CR 9.2 }\end{array}$ & \\
\hline
\end{tabular}

Engine used for analysis of emissions of $\mathrm{CO}$ and $\mathrm{CO}_{2}$ at different flow rates of oxygen is 3 cylinder 4stroke petrol engines. Exhaust gas analysis at various oxygen flow rates (i.e. 3lpm, 6lpm, and 9lpm) is carried out by using exhaust gas analyser.

\section{Results and discussion:-}

Enrichment of oxygen in the intake air results into complete combustion which results in the reduction in the emissions of the carbon monoxide. But the emissions of the carbon dioxide increases due to complete combustion.

Table 2: Emission readings

\begin{tabular}{|c|c|c|c|c|}
\hline \multirow{2}{*}{ Pollutants } & \multicolumn{4}{|c|}{ Flow rate } \\
\cline { 2 - 5 } & 0 LPM & 3 LPM & 6 LPM & 9 LPM \\
\hline $\mathrm{CO}(\%)$ & 0.16 & 0.11 & 0.10 & 0.08 \\
\hline $\mathrm{CO}_{2}(\%)$ & 2.89 & 4.82 & 4.53 & 5.45 \\
\hline
\end{tabular}

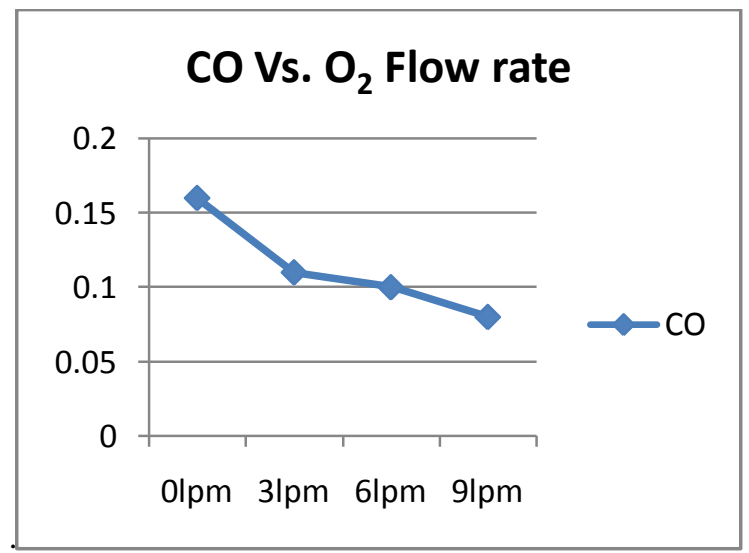

Fig 10: $\mathrm{CO}$ emissions vs $\mathrm{O}_{2}$ flow rate. 
This graph shows the variation of carbon monoxide $(\mathrm{CO})$ emissions at different oxygen flow rate i.e.31pm, 6lpm and 9lpm.Emissions of Carbon monoxide decreases with increase in flow rate of oxygen. Graph shows that carbon monoxide emissions are least at 91pm.

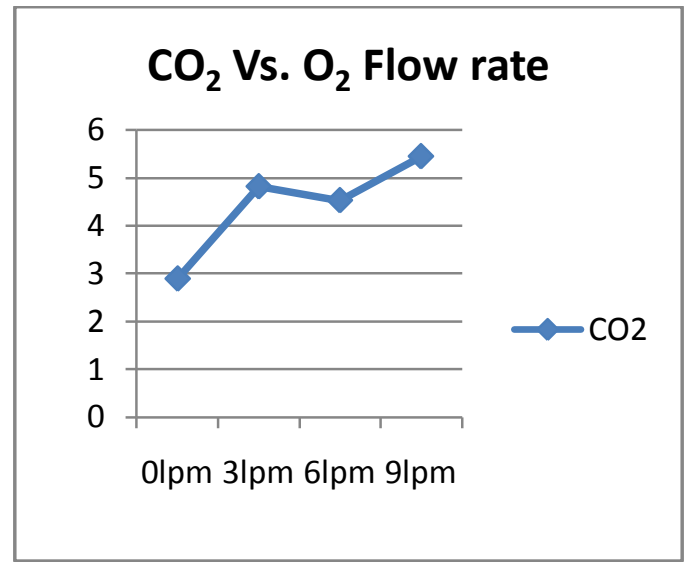

Fig 11: $\mathrm{CO}_{2}$ emissions vs $\mathrm{O}_{2}$ flow rate.

$\mathrm{CO}_{2}$ emissions increase with increase in oxygen concentration in the intake air. By comparing the results of emissions of $\mathrm{CO}_{2}$ at different flow rates, we get optimum results when the flow rate of oxygen is 6lpm.

\section{Conclusion:-}

1. There are various methods of oxygen enrichment like alcohol-gasoline blending, HHO-gasoline blending, biodiesel-gasoline blending and supply of pure oxygen from oxygen cylinder.

2. Among all the methods, injection of pure oxygen in the combustion chamber from oxygen cylinder is the simple and convenient method of oxygen enrichment.

3. There is no linear co relationship between emissions of $\mathrm{CO}$ and $\mathrm{CO} 2$ i.e. carbon monoxide emissions decreases with increase in concentration of oxygen in the intake air but carbon dioxide emissions increases with increase in flow rate of oxygen.

\section{References:-}

1. Technical bulletin "Nitrogen oxides why and how they are controlled" United States environment protection agency, November 1999

2. Eric M. Fujita, David E. Campbell and Barbara Zielinska "Final Technical Report on Chemical Analysis of Lubrication Oil Samples from a Study to Characterize Exhaust Emissions from Light-Duty Gasoline Vehicles in the Kansas City Metropolitan Area" National Renewable Energy Laboratory, December 21, 2006

3. Prof. S. P. Gautam "Status of the Vehicular Pollution Control Programme in India"Central pollution control board (ministry of environment \& forests, govt. Of india) east arjun nagar, delhi - 110 032,March, 2010

4. LU JIE "Environmental Effects of Vehicle Exhausts, Global and Local Effects- A Comparison between Gasoline and Diesel'Halmstad University, Year 2011.

5. Anil KB "Performance Enhancement of Engine Using Enriched Oxygen Inlet" International Journal of Science and Research (IJSR), Volume 4 Issue 4, April 2015,pp 1151-1157.

6. Juhi Sharaf "Exhaust Emissions and Its Control Technology for an Internal Combustion Engine"International Journal of Engineering Research and Applications, ISSN: 2248-9622, Vol. 3, Issue 4, Jul-Aug 2013, pp.947960

7. Wladyslaw Mitianiec,Krzysztof Sliwinski "Investigations Of Engine Exhaust Gas Emission With Oxygen Enriched Mixture And High Exhaust Gas Recirculation" Journal of KONES Powertrain and TransportISSN: 1231-4005, Vol. 21, No. 3 2014,pp 235-243

8. D.R.Gaikwad and H.M.Dange "Experimental investigation of four stroke SI engine using oxyrich air energizer for improving its performance"International journal of technology enhancements and emerging engineering research, vol 2, issue 7.2014.pp104-109. 